\title{
VISIONES Y REPRESENTACIONES: HISTORIA ORAL, IMÁGENES Y GUERRILLAS EN AMÉRICA LATINA
}

\section{VISIONS AND REPRESENTATIONS: ORAL HISTORY, IMAGES AND GUERRILLA WARFARE'S IN LATIN AMERICA}

\author{
José Rodrigo Rodríguez López*
}

\begin{abstract}
RESUMEN
El uso de la imagen y el testimonio como fuentes de investigación ha planteado nuevos retos y ha traído a discusión diversos problemas metodológicos y de análisis en el campo de las ciencias sociales. Bajo estas premisas, busca aproximarse al discurso audio-visual de los movimientos guerrilleros en América Latina, reuniendo dos vertientes novedosas e importantes en el campo de la historia: la historia oral y la historia gráfica. Reinterpretar estos acontecimientos forma parte de lo que falta por conocer de la historia reciente de América Latina a través de nuevas perspectivas.
\end{abstract}

PALABRAS CLAVE: AMÉRICA LATINA * FOTOGRAFÍA * HISTORIA ORAL * GUERRA * INVESTIGACIÓN HISTÓRICA

\section{ABSTRACT}

The use of image and testimony as sources of research has proposed new challenges and discussions about diverse methodological and analysis problems in the field of the social sciences. Based on the above, it is sought to come closer the audio-visual speech of the guerrilla movements in Latin America, bringing together two new and important aspects in the field of the history: the oral history and the graphical history. To reinterpret these events forms a part for knowing the recent history of Latin America across new perspectives.

KEYWORDS: LATIN AMERICA $*$ PHOTOGRAPHY $*$ ORAL HISTORY $*$ WAR $*$ HISTORICAL RESEARCH

Coordinación de Ciencias Sociales y Humanidades de la Universidad Autónoma de San Luis Potosí, México. chino_bass_1@hotmail.com 
"No importa lo que está detrás de la máscara, sino lo que simboliza". Subcomandante Insurgente Marcos.

"There does not import what is behind the mask, but what it symbolizes". Sub commander Insurgent Marcos.

Para Darío.

\section{INTRODUCCIÓN}

En este artículo se realiza un estudio histórico de la narrativa audio-visual de algunas agrupaciones guerrilleras como creadoras de un imaginario colectivo ${ }^{1}$ inscrito en una larga tradición guerrillera nacional y latinoamericana. A partir del análisis iconológico de una serie de fotografías requisadas en el trabajo de campo, además de entrevistas realizadas a Rodrigo Moya, fotógrafo especialista en los movimientos guerrilleros al ex comandante guerrillero Julio César Macías (César Montes), se señalará cómo la imagen y la historia oral pueden ser fuentes para reconstruir la genealogía histórica de las guerrillas en América Latina, centrándome finalmente, en la construcción de la imagen del Ejército Zapatista de Liberación Nacional (ezLN), así como, en la construcción de la imagen y el testimonio del Frente Guerrillero Edgar Ibarra (FGEI) en Guatemala, por ser dos ejemplos atípicos de dos movimientos de liberación nacional existentes en América Latina.

$1 \quad$ Por imaginario colectivo debe entenderse el conjunto de representaciones $y$ actitudes, tales como, el dinamismo propio, las actitudes colectivas, las necesidades $y$ los comportamientos de las personas en base a una sensibilidad socio-histórica, que constituye algún dominio de lo real e ideológico, lo cual hace referencia a las condiciones de gestación, sean de dominación, sometimiento o liberación de alguna representación determinada. En ese sentido, "imaginario colectivo" remite en este artículo, a la sociedad instituida $y$ no a la sociedad instituyente. Ver: Girola, Lidia. "Imaginarios socioculturales de la modernidad. Aportaciones recientes y dimensiones del análisis para la construcción de una agenda de investigación". Revista Sociológica 64. Año 22. México. Universidad Autónoma MetropolitanaAzcapotzalco, mayo-agosto 2007: 45-76.
Desde sus inicios, la imagen fija, gracias a su supuesta fidelidad con la realidad representada, desarrolló la ilusión al ser una prueba fehaciente de lo que ahí se retrata; sin embargo, la fotografía se caracteriza por ser más que nada un producto histórico y al utilizarla como fuente, hay que tomar en cuenta que esta siempre es una "representación". Así, a partir del momento de sus tomas, durante las cuales el fotógrafo actúa como intérprete $y$ como filtro cultural; a través del montaje que su producción necesariamente conlleva $y$ finalmente tomando curso a los usos inmediatos y posteriores, la misma imagen puede asumir significados diferentes, lo cual llega a depender también del contexto $y$ de las palabras que la acompañen, con lo que así, conforma un ícono-texto. La finalidad de este trabajo es señalar cómo dicho ícono-texto se conforma a partir de la fusión y el estudio de ambas fuentes de investigación como lo son la historia oral y la fotografía.

\section{SOBRE LA HISTORIA ORAL}

La historia oral busca preservar el conocimiento de los eventos históricos tal como fueron percibidos por los participantes (Collado, 1999). En este caso, a partir de esta metodología se manejan dos dimensiones en la fuente oral: la de su creación y la de su interpretación. En la primera, de inmediato se asume la parte subjetiva que conlleva, debido a que la entrevista es la técnica mediante la cual se recupera el testimonio, al presentar "frente a palabras, experiencias $y$ sujetos, $y$ a tratarlos con todas las distanciadas competencias profesionales, pero también con la respetuosa emoción que se siente ante personas y que no se experimenta tan vívidamente ante los documentos" (Portelli, 2006: 99).

En la recuperación de la concepción de las fuentes orales no debe perderse de vista que existen dos intereses presentes: el que tiene quien pregunta $y$ el que tiene quien ofrece su testimonio. El primero de ellos busca incentivar la memoria del segundo $y$ este va resignificando hechos que sucedieron en el pasado, los cuales a través de su memoria, los trae al presente. En ambos casos, 
debe reconocerse el papel activo que tienen los sujetos a lo largo de la entrevista y considerar que en torno a la explicación de los actos o hechos del sujeto, se encuentra presente la subjetividad de ambos (De la O Castellanos, 2006). En ese sentido, se introduce como campo de conocimiento, la subjetividad que rodea la vida de cualquier individuo.

El acercamiento a la historia oral siguiendo a De Garay (1997), permite valorar la riqueza de las historias de vida, las cuales llevan a conocer no solo al sujeto entrevistado sino más allá de su yo individual. Puesto que las historias de vida y el testimonio constituyen y cuestionan la práctica del historiador al exponerle el desafío de construir o reconstruir nuevas fuentes de información, en este caso, con base en la palabra de sujetos considerados invisibles (Acevez, 1997), los contextos creados permiten conocer sus relaciones sociales, su percepción de mundo, así como, la forma de interpretarlos desde su particular punto de vista. Los informantes elegidos para esta investigación fueron escogidos como señala Víctor Hugo Acuña (1989), por el significado de sus diversas experiencias - vistas como memorias confortables- $y$ por la pertinencia y relevancia de tales memorias para la investigación, ya que de esta forma, el material audio-gráfico requisado durante las entrevistas, forma por sí mismo un testimonio, en el que la imagen visual, la palabra escrita $y$ la historia oral son elementos que conviven y se complementan al capturar las expresiones de los informantes consultados durante la investigación ${ }^{2}$.

En términos metodológicos, los informantes fueron seleccionados dentro de un marco referencial con base en el pasado, con el fin de visualizar la identidad, dinámica e interacción de ambos sujetos sociales teniendo como factor común la guerra de guerrillas, uno siendo un guerrillero, quién en vez de un fusil cargaba una cámara y el otro siendo un

2 Donde la grabación requisada es el principal documento histórico, no la transcripción que se haga de esta; algunos autores aceptan una labor mínima. Ver: Sitton, Mehaffy y Davis, 1999: 90-91 y Acuña, 1989: 252. guerrillero, marcó a varias generaciones de hombres y mujeres en diversos países a lo largo de los años. A través de ambos testimonios, se proyecta una nueva visión de la historia que se identifica en un marco novedoso y alejado de la historia convencional o nacional, en el cual su testimonio audio-visual será una ventana que permite entender la evolución de las guerrillas en América Latina.

\section{SOBRE LA REPRESENTACIÓN GRÁFICA DE LOS MOVIMIENTOS ARMADOS}

La "representación" en su sentido más básico, de acuerdo con el Diccionario de estudios culturales latinoamericanos, es el resultado de un acto cognitivo por medio del cual se produce un signo o un símbolo que se instaura como "doble" de una presunta "realidad" o de un "original" (2009: 30-33). Al mismo tiempo, la representación constituye, la estructura de compresión a través de la cual el sujeto mira al mundo: sus cosmovisiones, su mentalidad y su "percepción histórica" (Szurmuk y MaKee, 2009). La representación se hace así portadora de un significado que se materializa a través del uso del lenguaje, sea escrito, visual, auditivo o corporal ${ }^{3}$.

$3 \quad$ El campo de la historia suele distinguirse de la literatura por su función de representar la realidad del pasado. Por esto mismo, se trata de una disciplina sensible al problema de la representación y a corrientes teóricas que a partir del posestructuralismo, han postulado un acceso al pasado necesariamente mediado. Por medio del positivismo, la búsqueda de objetividad impuso que la representación histórica, el relato histórico, se remitiera a fuentes escritas, documentos que atestiguaran y validaran científicamente una verdad histórica. Entre las corrientes del estudio de la representación en el campo político se podrían señalar tres categorías generales: la mimética, la intencionalista y la constructivista. Szurmuk y MaKee. Diccionario de Estudios Culturales Latinoamericanos, 2009: 30-33. 
Camilo Escobar (2000), señala que a lo largo de la historia, las sociedades se entregan a un trabajo permanente de invención de sus representaciones globales, como las ideasimágenes a través de las cuales, las sociedades muestran una identidad, perciben sus divisiones, legitiman su poder y elaboran modelos formadores para sus miembros, como por ejemplo, "el robín Hood" o el "buen ciudadano", representaciones de la realidad social y no simples reflejos de esta. Bajo esta interpretación, toda imagen encuentra lo imaginario, provocando la formulación de redes de identidad, poniendo en juego la "identidad del espectador" consigo mismo, como un espectador que observa con su "realidad".

El fotógrafo mexicano Rodrigo Moya, quien se desempeño como fotoperiodista de los movimientos guerrilleros de América Latina y entrevistado durante el curso de la presente investigación, coincide en las anteriores apreciaciones:

Bueno, cuando yo me dediqué al fotoperiodismo de los movimientos armados, lo que trataba de transmitir a la gente era la imagen proyectada de los guerrilleros, ya que muchas personas hablaban de los guerrilleros como seres mitológicos, mi trabajo en ese entonces, era mostrar la realidad de la guerrilla que es muy dura, que es una vida muy sacrificada; yo quería transmitir simultáneamente dos cosas: sus actividades militares, así como las actividades cotidianas sin llegar a una confrontación, aunque eso lo viví después en República Dominicana, pero, se trataba de mostrar qué es un guerrillero, quiénes son, cómo viven, ese era mi trabajo (Centro de las Artes de San Luis Potosí, 20/06/2012).

En las manos de las instituciones dominantes, la imagen fija acabó por ser un instrumento de control y de represión, al mismo tiempo que una herramienta funcional a la construcción de las identidades nacionales, a través, también de un proceso de inclusión y exclusión del auto-retrato social colectivo, dicho proceso a su vez ha dado origen a un "nacionalismo modular" ${ }^{4}$. Sin embargo, a partir de la década de los años 50 del siglo xx, la fotografía se rebeló en América Latina, contra sus antiguos dueños y se convirtió en un medio de representación de "identidades alternativas", de sujetos políticos tradicionalmente marginados y silenciados por las propagandas nacionales.

Julio César Macías (César Montes), quien fuera líder estudiantil en la década de los 60 en Guatemala y posteriormente, fuera comandante del Frente Guerrillero Edgar Ibarra (FGEI) -nombre en honor a un estudiante asesinado. Durante la década de los 70 fue uno de los fundadores del Ejército Guerrillero de los Pobres (EGP). César Montes describió algunas de las facetas que moldearon dicho cambio cultural y que marcaron el rumbo de la guerrilla en Guatemala:

El origen de los que participamos en el conflicto es diverso, son como que tres afluentes: el movimiento estudiantil, el movimiento izquierdista-marxista y los militares del 13 de Noviembre; ese componente, el de los militares del 13 de Noviembre dota al movimiento en sus inicios de un fuerte elemento patriótico nacional que no era nacionalismo acendrado que se opone al internacionalismo, sino al contrario, creo que el desarrollo de la conciencia socialista de los dirigentes del 13 que llevó a Yon Sosa hasta tener trotskistas en su movimiento hasta llegar a adoptar las ideas del marxismo, se complementa con la concepción del internacionalismo proletario (México DF, 23/03/2012).

$4 \quad$ Considerar al nacionalismo en América Latina como modular se debe en gran medida, a lo que para los Estados nacionales conlleva pensar y representar lo que debería ser una nación. Sin embargo, en México, a pesar de las pretensiones oficialistas de una identidad nacional, no hay una "mexicanidad" como en Guatemala y Perú no hay "guatemalidad" o "peruanidad". Estos países son construcciones políticas en base a cultivos, sentimientos y esperanzas de sociedades fragmentadas. Para nacionalismo modular, cfr. Anderson, 1993: 67 y Hobsbawm, 1992: 55. 
Fue a partir de la Revolución Cubana y aún más en la década de los 60 , cuando la fotografía, el cine y la música se afirmaran como herramientas para la producción "cultural" de los movimientos guerrilleros. Enrique Camacho Navarro (2006), afirma que con la Revolución Cubana todo aquello que representaba la realidad fue tomado como el curso de la mitificación. El rebelde, los rebeldes, empezaron a tomar el papel de símbolo, representaron identidad, admiración, confianza y cercanía. Rodrigo Moya señaló la importancia e influencia de la Revolución Cubana en América Latina:

La Revolución cubana dejo en mí profundas impresiones; las sigo teniendo, sigo estando de lado de la Revolución cubana con todo y sus tragedias; yo creo que la revolución cubana transformó las barreras del mundo y sobre todo, nos hizo comprendernos como latinoamericanos (Ciudad de Guatemala, 22/07/2013).

Sin embargo, en cuanto a la influencia en las guerrillas posteriores a la Revolución Cubana, César Montes manifestó la influencia que en sus palabras, el FGEI tuvo por parte del mundo exterior:

Primero quisiera decir que nosotros no teníamos tanta influencia de los cubanos como se ha creído y como incluso en algunos reportajes de algunas revistas se menciona. Tampoco teníamos ninguna relación con los rusos. En segundo, no teníamos nada que ver con los chinos, absolutamente nada, ni nunca tuvimos relación con ellos. Con los cubanos si tuvimos pero hasta que nosotros nos habíamos desarrollado. Entonces decir que uno no estaba influido por la revolución, la Revolución Cubana, pues no. Como un cubano me dijo a mí: Nosotros nos subimos a la sierra y luego bajamos echando bala $y$ tin-can tomamos el poder. Eso me dio mucha risa porque luego hacíamos caricatura de eso, verdad. Si vamos a hacer alguna cosa hagámosla ahorita aquí en can, como los cubanos, casi como una improvisación. Entonces no teníamos mayor influencia, ya después de un tiempo... los cubanos duraron dos años y medio en su revolución, en su guerra de guerrillas. Nosotros ya teníamos 3 años cuando hicimos contacto con ellos (Ciudad de Guatemala, 22/07/2013).

En este trabajo, la idea de identidad no es algo estable, permanente ni duradera; más bien, se emplea la palabra "identización" (traducción libre de la palabra Identization) término que indica, según Alberto Melucci (1995), el proceso dinámico en que se basa la noción de identidad. Pero, como los movimientos sociales se proponen reemplazar "un sistema de creencias dominante que legitima el status quo por otro alternativo que apoye el cambio provocado por la acción colectiva", los participantes en el movimiento viven los atavíos y ostentan los símbolos de la revuelta para ganar apoyo y distinguirse de sus enemigos (Melucci, 1995: 51). Sin embargo, existe una paradoja en la política simbólica de los movimientos sociales, que se debate entre la implantación de símbolos dinámicos que crean identidades nuevas y provocan el cambio, así como, el uso de símbolos conocidos con raíces en su propia cultura (Tarrow, 1997).

Para el análisis de los movimientos armados, el tema de la identidad es de vital importancia porque su definición permite la construcción de solidaridad interna en un determinado grupo, su capacidad de auto-reconocerse y al mismo tiempo, ser reconocidos. En la historia de las guerrillas, las construcciones identitarias y las ideologías firmes marcaron efectivamente, una frontera insuperable entre el "adentro" y el "afuera".

\section{SOBRE LOS NOMBRES Y LAS BANDERAS}

La lucha por los símbolos acompaña todos los movimientos sociales $y$ ha dado lugar a una verdadera negociación simbólica, en el cual las imágenes de los héroes nacionales han sido objeto de diferencias entre los grupos armados y sus enemigos. Así, por ejemplo en Nicaragua, el Frente Sandinista de Liberación Nacional (FSLN) empezó usando la imagen de Augusto César Sandino, así 
como, el uso de su nombre, ya que este marcaba la identificación del neo-sandismo con la consigna política lanzada por el Sandinismo histórico: "patria libre o morir".

No obstante, en este país, el dictador Anastasio Somoza había escrito un libro donde creaba una imagen adversa sobre Sandino y su ejército, apareció con un retrato fotográfico del primer Sandino a sus espaldas, cuando el Frente Sandinista ya conquistaba las ciudades más importantes del país; así como, la imagen constante de José Martí en Cuba, su uso por parte del dictador Batista y su irrenunciable presencia a partir de la lucha hasta el triunfo de la Revolución Cubana 5 .

Sin embargo, la ubicación de las imágenes como generadoras de imaginarios colectivos forma parte del legado guerrillero en América Latina, un ejemplo de esta afirmación son las fotografías hechas a Ernesto Che Guevara, las cuales han generado una representación simbólica sobre la figura de "el guerrillero" o "el revolucionario". Rodrigo Moya, quien estuvo en La Habana durante el triunfo de la Revolución cubana $y$ algunos años posteriores a la misma, llevo a cabo una serie de tomas en las que reprodujo algunas fotografías hechas al comandante Ernesto Guevara, así como, las que efectuó al comandante César Montes durante su estancia en la Sierra de las Minas con la guerrilla Edgar Ibarra.

Asimismo, Moya realizó la siguiente reflexión:

Yo creo que no es su imagen, sino más bien, el que trasciende ha sido el propio Ernesto Che Guevara, en su trabajo político, guerrillero y su acción revolucionaria; mis fotografías son afortunadamente, un medio en un momento oportuno; yo no soy más que un instrumento que transmite una serie de imágenes del Che hechas en 1964.

Y pues a César Montes lo conocí muy bien, cuando yo estuve allí en la Sierra de las Minas, era un muchacho igual que yo pero ya líder de la guerrilla, o al menos era cuando yo estuve ahí con él, siempre me trató bien él y los demás siempre procuraron mi seguridad antes que la de ellos, son cosas que uno no olvida (Centro de las Artes de San Luis Potosí, 20/06/2012).

En América Latina, es fundamental considerar que, desde la aparición de la guerrilla de la Sierra Maestra hasta la aparición del ezLn en Chiapas, las banderas de todas las agrupaciones político-militares ${ }^{6}$ fueron rojinegras. Además de que algunas adoptaron el nombre de "Liberación Nacional"7, muchas de las guerrillas de la década de los años 70 y mediados de los 80 trazaron, desde su inicio, una importante genealogía, marcada por la herencia de los conflictos armados de la década de los 60. Así, muchas de las referencias simbólicas, por ejemplo, de las guerrillas centroamericanas pueden verse como elementos heredados del marxismo latinoamericano (las banderas rojinegras, las estrellas de cinco puntas y las figuras de héroes locales). No

$6 \quad$ Estas organizaciones se definen como agrupaciones en donde se aglutinan variados sectores de la sociedad, los cuales se caracterizan por tener una ideología que se basa en un nacionalismo intenso, el antiimperialismo o anticolonialismo; una utopía socialista y el advenimiento de una revolución social por la vía armada. Casi todos esos movimientos hacen diferencia entre "cooperantes", "militantes" y “combatientes". Kruijt, 2009; 29-32.

$7 \quad$ Las luchas de la liberación nacional en los países dependientes son las luchas concretas de sus reivindicaciones sociales. La liberación nacional implica el cuestionamiento del sistema de propiedad impuesto por el imperialismo y sus socios nativos. En ese sentido, la liberación nacional en América Latina es constituida por el nacionalismo de los pueblos que luchan por liberarse y dentro de estos, quienes sufren en mayor grado del dominio imperialista. Este nacionalismo revolucionario o liberación nacional (como sentimiento $y$ conciencia liberadora) desempeña un papel de primera línea en todas las revoluciones que fueron triunfantes o que siguieron ese curso (FLN-Argelia, FLN-Vietnam, ELN-Bolivia, ELN-Colombia, FMLN-El Salvador, FSLN-Nicaragua y EzLN-México), con lo cual, la lucha de liberación nacional se convierte en una lucha nacional antiimperialista, es decir, se transforma en una lucha de liberación contra todo tipo de opresión social. Boersner, 1983: 80-89.

$5 \quad$ Véanse los trabajos de Camacho Navarro, 1991 y 2007. 
obstante, algunos de estos distintivos no coincidieron siempre con el marxismo clásico ${ }^{8}$.

Por ejemplo, en Guatemala, El Ejército Guerrillero de los Pobres (EGP) intentó congeniar los semblantes de la clase y etnia coaligándolos en la llamada cuestión étnico-nacional (Payeras, 1998). Paralelo a esta agrupación, a mediados de la década de los años 70, surgió la Organización Revolucionaria del Pueblo en Armas (ORPA), la cual salió a luz pública en 1979, realizando una crítica sobre la etapa insurgente de la década anterior y sobre el olvido de la población indígena. Para esta organización, el sujeto o actor social principal era el indígena, con lo cual orientaba su ideología en una reivindicación étnica (Santa Cruz, 2004: 61), presentando entre sus objetivos el acceso e incorporación de los indígenas a la plena ciudadanía. Sin embargo, la guerrilla de aquellos años tenía una estrategia definida para acercarse a la población maya. Según César Montes, ellos fueron llevados a las comunidades, donde el guerrillero encuentra clases sociales, no mayas que defienden su identidad $y$ su cultura:

Es un problema que debe verse a la luz de la lucha de clases, lo que nos divide no es lo étnico sino lo de las clases sociales, nos une más con los indígenas la explotación que lo que nos divide a los indígenas de los ladinos. Yo me niego a aceptar que se autodenominen mayas, porque no son mayas, en todo caso de origen maya, o son mayences o que se denominen naturales, ¿̇o tú eres artificial o qué

$8 \quad$ En Guatemala por ejemplo, la ausencia de una figura nacional como la de Sandino en Nicaragua o la de Farabundo Martí en El Salvador, la imagen de "el guerrillero" fue construida a partir de la figura de algunos de los insurgentes que habían muerto en circunstancias desiguales en contra del ejército nacional y sus nombres fueron tomados por algunas de las guerrillas de los años 70 y 80 para designar los frentes de guerra donde estos luchaban; o bien, se tomo la imagen y el nombre de Ernesto Ché Guevara para designar no solo el frente del EGP que operó en el departamento de Huehuetenango, sino para nombrar a la organización armada, donde el Che Guevara se convirtió en símbolo del sacrificio personal en nombre de una revolución. Véase: Santa Cruz, 2004: 84. diablos eres? O sea soy natural porque soy nativo de aquí, no nací en Suiza o Chihuahua, tan natural soy yo como tú, $y$ nos ponen en la madre los ricos $y$ los terratenientes, $y$ la represión nos agarra parejo a todos, entonces yo creo que hay que entender su especificidad, su peso que tiene en la sociedad pero no sobre la base de hacer ya la división entre mayas $y$ ladinos.

Porque además de eso, ¿quién representa a todos? Somos un país multilingüe, de muchas culturas $y$ de muchas etnias, $y$ no hay una etnia que las representa a todas: un quiché no se siente keckchí, un zutujil no se siente ixil; ni se entienden ellos mismos, es como en México, un tarahumara no tiene nada que ver con un indígena de los Altos de Chiapas, ni se conocen ni se identifican; en Guatemala durante toda una época, el despertar de la integración a la vida política de los mayas se hizo a través de la insurgencia revolucionaria (México DF, 23/03/2012).

Por otra parte, el EzLn, el cual basa su ideología en algunos símbolos, pero en el lenguaje escrito $y$ oral opera un distanciamiento con respecto al violento lenguaje anti-yankee de los movimientos del pasado. Frente a las declaraciones públicas del poder que los retrata como agitadores profesionales de la violencia provenientes del extranjero, el EzLN insistía en deslindarse de las luchas del continente, principalmente de la guatemalteca y la salvadoreña (Leyva, 2006).

\section{SOBRE LOS PAISAJES}

Al ver distintas imágenes de las guerrillas latinoamericanas, muchas fueron realizadas en lo que en el artículo se denominará "paisaje silvestre", como fondo adecuado para la toma de las fotografías a los diversos grupos insurgentes. En este sentido, Laura Castellanos y Ricardo Trabulsi (2008), señalan la tradición de la imagen de las guerrillas latinoamericanas de los años 60 y 70, las cuales en este tiempo, 
escondidas en las serranías y selvas, muchas de estas agrupaciones armadas se hicieron retratar en su entorno por fotógrafos profesionales que se aventuraban por largos caminos para llegar a conocerlos (2008: 30). Las imágenes eran publicadas en revistas, las cuales muchas veces apoyaban el proceso revolucionario latinoamericano, querían dar conocimiento a la sociedad sobre la existencia misma de los grupos armados; negada hasta el último por los regímenes autoritarios correspondientes.

Rodrigo Moya lo expresó de la siguiente manera:

- Bueno, para mí la fotografía como arte por el arte nunca me interesó, me interesó como un medio para adentrarme en la realidad y conocerla; yo creo que decidí ser fotógrafo de los movimientos armados por sensibilidad y educación política; con el tiempo uno se va politizando hasta un punto en que llegas a adentrarte en ese mundo, donde yo sólo fui un médium que transmitió a través de imágenes, el trabajo político, y revolucionario de los grupos disidentes de América Latina, eran épocas distintas; los grupos en el poder no lo admitían, como aquí en México, cuando surgieron las primeras guerrillas, el gobierno dijo que eran grupos de bandidos, pero en su mayoría eran jóvenes universitarios influenciados por el inminente triunfo de la revolución cubana (Domicilio personal, ciudad de Cuernavaca, Morelos, 25/07/2012).

La identificación del guerrillero y la selva, lugar donde se esconde su identidad y práctica de las armas, es un tópico tanto de la memoria visual como de las memorias escritas de las experiencias del pasado. Sin embargo, el desvelamiento del secreto escondido en la selva pone entonces en riesgo la vida de los combatientes, al mismo tiempo que alimenta su lucha; así, por ejemplo, en México, en 1965, la existencia de un grupo guerrillero en el estado de Chihuahua fue revelada por un reportaje fotográfico publicado en la revista Sucesos para todos, con fotografías de Rodrigo Moya ${ }^{9}$ y textos de Víctor Rico Galán.

Las imágenes de los cuerpos sin vida de los atacantes del cuartel Madera resultó una de las primeras pruebas de la existencia de grupos guerrilleros en México; sin embargo, los militares ya tenían conocimiento de la organización, como lo revela Jaime López (1974), para las autoridades militares, así como, en la prensa oficialista, los rebeldes eran identificados como "gatilleros" y "bandidos comunes", con lo cual, el Estado pretendía crear a través del leguaje una efigie negativa de los insurgentes (López, 1974: 14-20).

La falta de palabras por parte del poder dominante, para nombrar la existencia misma de los actos rebeldes, deriva en buena medida de razones estratégicas; por un lado, el público de las ciudades no tiene idea y por otro lado, no se le reconoce al grupo como fuerza combatiente, por lo cual el Estado interviene con fuerzas militares o paramilitares directamente en el territorio. César Montes, al describir en sus propias palabras las verdaderas motivaciones sobre el levantamiento militar del 13 de noviembre de 1960:

-Ydígoras dijo que era un movimiento comunista, fue lo primero que dijo, hábilmente dijo que era un movimiento comunista que nosotros, como estudiantes liderábamos, ese tipo de babosadas, ése era un movimiento sin ideología, era un movimiento eminentemente reivindicativo de la mayoría de oficiales jóvenes como Luis Turcios Lima que no veían con buenos ojos las políticas del gobierno de Ydígoras Fuentes y desde el luego tenían elementos civiles como yo, que simpatizábamos con el movimiento a eso se reduce todo. No era una rebelión comunista ni anticomunista, no, querían cambiar el gobierno por un gobierno representativo, trabajador, honesto y eficiente (Ciudad de Guatemala, 22/07/2013).

9 Moya, Rodrigo. Ensayo, memoria y crónica. México: Ediciones El Milagro, 2004. Moya, Rodrigo. "La cámara sola". El catálogo fuera de moda. Homenaje a Rodrigo Moya. Obra fotográfica 19551968. México: CONACULTA-INAH, 2002. 


\section{LOS PASAMONTAÑAS, LOS PALIACATES: VESTIMENTA DEL COMBATIENTE}

Si el rostro siempre ha representado el foco de los retratos de los héroes guerrilleros, los grupos armados, en la mayoría de los casos, por obvias razones de seguridad debido a su condición de clandestinidad, han tenido que esconder su cara al enemigo, al menos hasta que las revoluciones no triunfaran. En Nicaragua, por ejemplo, los guerrilleros usaron en los momentos iniciales de la lucha, las máscaras de los bailes indígenas tradicionales como en la comunidad indígena de Monimbó para esconder su identidad individual. Posteriormente, cuando muchas ciudades eran poder del Frente Sandinista, se limitaron a usar máscaras de esquiar o paliacates (Meiselas, 2008).

Cuando el $1^{\circ}$ de enero de 1994, el EzLN hizo su aparición pública, todavía algunos de los rostros de los zapatistas estaban cubiertos por pasamontañas; algunos llevaban fusiles $y$ ropa café estilo militar que no dejaban lugar a dudas; pero los demás llevaban ropas de uso cotidiano y cada quien tenía un paliacate rojo. Según comenta el subcomandante Marcos (2008), en sus inicios el uso del pasamontañas fue un medio para esconder su identidad de los activistas de las comunidades, que tenían represalias de autoridades o vecinos. Pero gracias a los medios, el pasamontañas se transformó en un símbolo, debido sobre todo al atractivo misterio que necesariamente reside en la máscara, como lo explica Marcos (Flores, 2004). Sin embargo, inicialmente el símbolo escogido por los rebeldes había sido el paliacate rojo que tiene una larga tradición en las zonas rurales, donde representa un elemento útil para el trabajo de campo. Aunque es cierto que el elemento de la vestimenta más conocido del ezLn es el pasamontañas; los comunicados contribuyen a dar un valor metafórico y poético a este objeto que favorece además, el proceso de "identización" necesario para ganar las simpatías y el favor de la sociedad civil. Así, el pasamontañas es el "rostro de los sin rostro" y cualquiera puede llevarlo.

César Montes señaló la vestimenta usada por él durante su estancia en la Sierra de las
Minas en la década de los 60, así como, el armamento utilizado por la guerrilla Edgar Ibarra:

- César Montes usaba una gorra del ejército de Guatemala que había "recuperado" de un combate en la Ruta al Atlántico. Tenía una estrella que era de Capitán del Ejército de Guatemala. Dicen que por esto Turcios Lima lo nombró Capitán Guerrillero. Tenía un arma Schmeisser alemana, sub ametralladora, calibre 9 milímetros $y$ dicen que no fallaba un tiro nunca. El paliacate rojo que usaba al cuello era como un amuleto de origen mexicano con el que secaba el sudor. Siempre tenía reserva mientras lavaba uno, usaba otro. Usaba lentes permanentemente pero nunca se dejo tomar fotos con lentes, no por vanidad, sino porque era en elemento distintivo por el que podrían reconocerlo. Usaba indistintamente una boina verde, una negra o la gorra del ejército que dicen le traía suerte. Decían que con esos lentes era que podía ver de noche, que por eso caminaba tan rápido en la oscuridad.

Rocael utilizaba una Thompson calibre $.45 \mathrm{~mm}$; una carabina 30-M1, norteamericana usada por el Gallo Giro; una sub ametralladora Madsen $.9 \mathrm{~mm}$ de fabricación brasileña del Güero; una sub ametralladora Thompson calibre $.45 \mathrm{~mm}$ de Benedicto; dos carabinas americanas M-2 recortadas una de Rosa María y otra de Darío; y pues yo con la Schmeisser alemana. Luego llegó un fusil M-16 que usé como primicia porque era un arma que estaba experimentándose en Vietnam, en esos momentos. Yo tuve la versión deportiva $y$ realmente era un tesoro (México DF, 23/03/2012).

En torno a la cuestión diaria en la vida guerrillera, Rodrigo Moya realizó una serie de imágenes a la guerrilla Edgar Ibarra, retratándolos en sus labores cotidianas, en sus caminatas por la selva de Guatemala, pero también realizando acciones militares $y$ de propaganda 
armada; es decir, tácticas y estrategias guerrilleras. Todas bajo un discurso visual armónico con una carga social importante, donde el estilo personal de Moya se transmite claramente. Recordando la estancia de Moya en su campamento guerrillero, César Montes mencionó las condiciones de la llegada del fotógrafo:

- Nosotros lo que queríamos era mostrar que los guerrilleros éramos guatemaltecos, que estábamos vivos, porque se hacía una especie de mito, algo así como que muy poca gente del ejército nos había visto, decían que nos buscaban y no aparecíamos, de ahí el término que usaban en la montaña, que se desaparecen y son como fantasmas. Nosotros estábamos mostrando que sí podíamos, habría que desmitificar eso, humanizarlo, darle una dimensión humana y que la gente supiera de nosotros, se alzara y se formara.

Rodrigo Moya fue una figura más asociada a nosotros a diferencia de su compañero Mario Menéndez, Moya era una imagen más asociada al guerrillero. Joven, atlético, deportivo, Rodrigo tenía más que ver con nosotros, por ejemplo, él destacó más el papel de la mujer en la guerrilla. A Rosa María (la única guerrillera del núcleo inicial del fGeI) no se le ha dado el debido valor, la importancia debida, Rosa María queda reducida a zurcidora de pantalones $y$ a servidora de comida como es tradicional que una mujer guadalupana haga, ¿verdad? En cambio Rodrigo Moya la fotografió con su arma en mano, la fotografió en la marcha con su mochila en mano, es decir, sus ojos, su lente y su conciencia si percibieron la esencia real de nuestra lucha (México dF, 23/03/2012).

Como lo afirma Ricardo Melgar Bao (2006), la construcción cultural de las virtudes violentistas en las guerrillas latinoamericanas de los años 60 y 70, exaltaban un patrón de simbolización fuertemente masculinizado, que jugaba con la equivalencia entre lo viril $y$ lo heroico (2006: 29-32). Así, en las imágenes que tomaron los fotoperiodistas de los grupos guerrilleros de antaño, la presencia de las armas era un elemento constante, como se aprecia en las imágenes que Rodrigo Moya tomó en la selva de Guatemala en 1965.

\section{LA IMAGEN DEL EZLN EN EL SIGLO xxI: DEL FUSIL AL TELÉFONO SATELITAL}

Una de las características del Ejército Zapatista de Liberación Nacional (EzLN) y la que quizás contribuyó a la formación de un fuerte consenso entre la sociedad civil nacional e internacional, entre militantes laicos y grupos de inspiración católica, es la de ser un "ejército" que aspira a su propia desaparición, que no quiere tomar el poder $y$ que ha llegado a reemplazar el poder de las armas por el poder de las palabras, o hasta del silencio.

A través de toda una serie de símbolos, textos y testimonios, el movimiento zapatista ha replanteado la temática de la violencia; en los comunicados la "tierna furia" que arma la esperanza, no anhela a la conquista del poder sino a algo más difícil: un mundo nuevo. El tema de las armas y la violencia nos reconecta necesariamente al tema del martirio ${ }^{10}$, el cual ha caracterizado las memorias de las experiencias guerrilleras a lo largo $y$ ancho del continente; aquí se da entonces otra ruptura importante en el documento "Para que no sean necesarios los soldados ni los ejércitos" (6 de marzo de 1994), el Subcomandante Insurgente Marcos escribe:

Abandona si lo tienes, el amor por la muerte y la fascinación por el martirio. El revolucionario ama la vida sin

10 Quienes decidieron empuñar las armas para impulsar el proyecto revolucionario fueron portadores de la idea según cual, era preferible morir a vivir en condiciones sociales de marginalidad. Explorar por qué la muerte, como el paso a la perennidad, significó dar la vida por el pueblo, quien a su vez tendría bajo su control, la responsabilidad de recordar para siempre a los mártires, fueron creencias que configuraron una actitud de inmolación ante la cual era bien visto matar o morir, puesto que el ideal - la revolución y la inmortalidad - iban más allá del derecho a la vida $y$ por qué no, a bien morir (Carrillo, 2012). 
temer la muerte, $y$ busca que la vida sea digna para todos, $y$ si para eso debe pagar con su muerte lo hará sin dramas ni titubeos (García de León, Monsiváis y Poniatowska, 2003: 192).

Este nuevo guerrillero del siglo xxi se distingue de sus antecesores por un nuevo objeto del qué hacer, que en la iconografía sustituye la presencia del arma: el teléfono satelital. Es bien conocida y en parte sobrestimada, la importancia de los nuevos medios de comunicación para la guerrilla chiapaneca y el impacto que tuvo a nivel del imaginario global, por consiguiente, el neozapatismo trasladó a los territorios virtuales, ofensivas que tuvieron resonancia a escala internacional, debido a la masificación de la información a través de la red (Leyva, 2006).

\section{LA GUERRILLA EDGAR IBARRA Y LA CONSTRUCCIÓN DE UNA IMAGEN GUERRILLERA}

En Guatemala, a diferencia de otras guerrillas muy identificadas con la Revolución cubana, las Fuerzas Armadas Rebeldes (Far) $y$ uno de sus principales brazos armados, era dar a conocer su lucha y mostrar que lo que se estaba haciendo en Guatemala podía repetirse en otros países de la región centroamericana, como años más tarde se llevaría a cabo en Nicaragua y en El Salvador, en las cuales, a diferencia de la cobertura que tuvo el $1^{\circ}$ de enero de 1994 a nivel mundial, las primeras imágenes $y$ documentos como artículos y publicaciones difundidas sobre la guerrilla guatemalteca, revelan cómo fueron consideradas propaganda subversiva por el Estado y el ejército guatemalteco, pues el ser descubierto en posesión de alguno de los ejemplares de la revista Sucesos para todos ${ }^{11}$, principal órgano de información, significaba la muerte. Sin embargo, su difusión de manera clandestina, permitió crear una

11 Revista Mexicana dirigida por Mario Menéndez, en la cual Rodrigo Moya se desempeñó como foto-reportero. La cobertura de dicha revista es fundamental para entender la historia gráfica de las guerrillas en América Latina, ya que cubrió con diversos reportajes la historia y el desarrollo de las guerrillas en varias partes del continente americano. imagen sobre los guerrilleros guatemaltecos hasta entonces, desconocida para la sociedad y el mundo en general.

Es en Guatemala donde por primera vez, después de la Revolución cubana, en América Latina se presentó una nueva interpretación de un nuevo grupo armado revolucionario y la imagen que conllevaba a los guerrilleros. Este nuevo grupo armado muy distante $y$ ajeno a los cubanos, originado como el enlace entre ex oficiales del Ejército de Guatemala, estudiantes universitarios $y$ algunos campesinos, conformó a una guerrilla alentada y auspiciada bajo distintas doctrinas $y$ formas de pensamiento: desde el nacionalismo hasta el marxismo-leninismo y el trotskismo. La imagen de dicha guerrilla jugó un papel fundamental para la comprensión de la lucha que sostenían estos actores armados, pues ayudó a romper el cerco informativo que las grandes transnacionales periodísticas y las oficinas de propaganda de Guatemala, en colaboración con Estados Unidos y otros gobiernos dictatoriales, tendieron sobre Guatemala y otras naciones del continente americano. Partiendo de esto, la cobertura del Frente Edgar Ibarra constituye un significativo aporte al uso de la imagen como fuente para la historia latinoamericana, convirtiéndose en el primer reportaje publicado en un medio de comunicación masivo concedido por un grupo guerrillero, en un momento en que la guerrilla de Guatemala iniciaba su lucha.

\section{CONCLUSIÓN}

A través de esta serie de ejemplos generales y particulares, se han intentado demostrar las pautas sobre la representación de los "actores armados" en América Latina, las cuales se nutren de imaginarios múltiples para hacer uso creativo, capaces de recuperar la simbología cristiana, las creencias populares y el discurso de las izquierdas internacionales. El discurso gráfico de representación de las guerrillas ha sido un discurso incluyente, ya que ha sabido moverse - con algunos tropiezos- entre diferentes horizontes: el global, el nacional y el regional. La antigua subordinación de los medios de comunicación al Estado, como la prensa, la radio y la televisión por medio de la censura y la 
autocensura, hacían cerrado el acceso a la imagen y la voz de los insurgentes evidentemente anti-capitalistas, localizados en la frontera sur del país norteamericano. No era limitada la situación si se recuerda la lucha encabezada por los Estados Unidos, en contra del comunismo en el continente americano.

En el caso de México, el zapatismo, consciente de la importancia de la solidaridad internacional que había sido puesta en práctica $y$ en experiencia como en las guerrillas en Nicaragua, Guatemala o El Salvador, ha sabido jugar con diferentes identidades, correspondientes a los distintos planes de lucha y que van desde las más específicas (la indígena) hasta las más generales (la humanidad entera). El abandono del leguaje épico, de la solemnidad $y$ de la tragedia que caracterizaron por obvias razones, el relato y la memoria de las experiencias continentales pasadas, desaparecen en el lenguaje visual y escrito del llamado neozapatismo, debido a las "posdatas" que rompen con la forma misma del comunicado. Finalmente, la originalidad de la representación de la guerrilla chiapaneca, ampliamente transmitida por $y$ en parte re-elaborada, a través de los nuevos medios de comunicación, reside en buena medida en la capacidad de darle la vuelta al discurso militante "clásico", abriendo así el campo de la militancia y la representación a un conjunto de sujetos provenientes de diferentes movimientos sociales.

En ese sentido, la propuesta del EzLn reside en su "apertura discursiva", en una voluntad y capacidad dialógica que ha permitido incorporar una vasta gama de activistas sociales en un proyecto colectivo único. La capacidad incluyente ha sido en gran medida amplificada por el uso de símbolos en el lenguaje visual, gracias a la inclusión o a la ausencia de elementos conocidos que dan lugar a un mensaje novedoso (las banderas, el paisaje, el pasamontañas, la sustitución del arma y la presencia de mujeres).

En Guatemala, la información proporcionada por ambos informantes permitió contextualizar la imagen $y$ la cobertura que tuvo la presencia de "los guerrilleros", su conformación, sus tácticas y su vida cotidiana dentro del grupo, así como, la personalidad de cada uno de los miembros, todas estas piezas claves que juntas dan forma a una narrativa audio-visual armónica con una carga social importante, donde el testimonio y la imagen revelan la imagen de una guerrilla alejada de la influencia cubana $y$ se acercan a una visión detallada de la realidad guatemalteca, donde la represión y la desigualdad marcaron a esta y las demás generaciones posteriores que decidieron empuñar las armas para llevar a cabo su utopía armada.

Tal y como afirma Graciela de Garay, la información obtenida a través de la historia oral permite corregir o aclarar las interpretaciones historiográficas cuando se refieren a un orden temático particular (De Garay, 1999). En ese sentido, el testimonio de Rodrigo Moya es una pieza clave para comprender la historia de los movimientos armados de la segunda mitad del siglo xx desde una óptica diferente, relacionada con la fotografía como proyectora de la imagen de una realidad y momento específicos. En este sentido, el cotejo de la serie de fotografías de este autor con algunas otras de la misma secuencia temática, así como, el testimonio de él, permite identificar y comprender la estrategia envolvente, casi cinematográfica, con la que Rodrigo Moya estudiaba atmósferas y personajes considerados invisibles por la historia; además, se integraba tanto de una manera directa como armónica. En ese mismo sentido, el cúmulo de información aportada por el comandante César Montes, permitió hilvanar los testimonios con las imágenes y el "otro testimonio" de quien hace más de 40 años, fue el primer fotógrafo en realizar una estancia con la guerrilla a su responsabilidad, teniendo como soporte la revisión historiográfica, hemerográfica y las historias de vida, sobre los tres temas abordados en esta investigación: la imagen, las guerrillas en América Latina y la imagen de sí mismos que hoy hacen dos personajes fundamentales de ambos sucesos en años pasados.

\section{BIBLIOGRAFÍA}

Aceves Lozano, Jorge. "Un enfoque metodológico de las historias de vida". Cuéntame tu vida, historia oral, historias de vida. Graciela De Garay (coord.). México: Instituto Mora, 1997. 
Acuña, Víctor. "La historia oral, las historias de vida y las ciencias sociales". Historia, teoría y métodos. Elizabeth Fonseca (ed.). Costa Rica: EDUCA, 1989.

Anderson, Benedict. Comunidades imaginadas: reflexiones sobre el origen y la difusión del nacionalismo. México: Fondo de Cultura Económica, 1993.

Boersner, Demetrio. "Marx, el colonialismo y la liberación nacional". Revista Nueva Sociedad 66. Buenos Aires, Argentina. Fundación Friedrich Ebert, mayo-junio 1983: 80-89.

Camacho Navarro, Enrique. "Fidel Castro: la construcción de un rebelde (1953-1959)". América Latina: permanencia y cambio. México: Centro Coordinador y Difusor de Estudios Latinoamericanos-Universidad Nacional Autónoma de México (CCYDELUNAM), 2007.

Camacho Navarro, Enrique. Los usos de Sandino. México: Centro Coordinador y Difusor de Estudios LatinoamericanosUniversidad Nacional Autónoma de México (CCYDEL-UNAM), 1991.

Camacho Navarro, Enrique (coord.). El rebelde contemporáneo en el Circuncaribe. Imágenes y representaciones. México: Centro Coordinador y Difusor de Estudios Latinoamericanos-Universidad Nacional Autónoma de México (CCYDELUNAM), 2006.

Carrillo Padilla, José Domingo. "Las actitudes ante la muerte: testimonios de los movimientos armados guatemaltecos". Etnia, género y case en el discurso y la práctica de las izquierdas en América Latina. Miguel Ángel Urrego y José Domingo Carrillo Padilla (eds.). México. Universidad Michoacana de San Nicolás de Hidalgo-Universidad Autónoma de San Luis Potosí, 2012: 253-269.

Castellanos, Laura y Trabulsi, Ricardo. Corte de Caja. México: Editorial Bunker, 2008.

Castoriadis, Cornelius. Los dominios del hombre: las encrucijadas del laberinto. 2nda. edición. Barcelona, España: Gedisa, 1994.
Collado Herrera, Ma. Del Carmen. "¿Qué es la historia oral?”. La historia con micrófono. Graciela de Garay (coord.). México: Instituto Mora, 1999.

De Garay, Graciela (coord.). Cuéntame tu vida, historia oral, historias de vida. México: Instituto Mora, 1997.

De Garay, Graciela. "Fidel Castro: la construcción de un rebelde (1953-1959)". América Latina: permanencia y cambio. Enrique Camacho Navarro (ed.). México: Centro Coordinador y Difusor de Estudios Latinoamericanos-Universidad Nacional Autónoma de México (CCYDEL-UNAM), 2007.

De Garay, Graciela. Los usos de Sandino. México: Centro Coordinador y Difusor de Estudios Latinoamericanos-Universidad Nacional Autónoma de México (CCYDELUNAM), 1991.

De Garay, Graciela. Reflexiones sobre el oficio del historiador. México: Universidad Nacional Autónoma de México (UNAM), 1999.

De la O Castellanos Pinzón, Ana María. "Las fuentes orales en la historia de la migración mexicana del siglo xx". Revista del Seminario de Historia Mexicana. Historia Oral 2 (6). México: Universidad de Guadalajara-Centro Universitario de los Lagos, 2006.

Escobar, Juan Camilo. Lo imaginario. Entre las ciencias sociales y la historia. Medellín, Colombia: Editorial Cielos de Arena, 2000.

Flores Quintero, Genoveva. La seducción de Marcos a la prensa. Versiones sobre el levantamiento zapatista. México: Tecnológico de Monterrey-Porrúa, 2004.

Figueroa, Luis. "Golpe de mercado, un nuevo 'circle wanking”". Carpe Diem. Martes 03 de agosto de 2010. En: <http://luisfi61. blogspot.mx/2010/08/golpe-de-mercadoun-nuevo-wanking.html>.

García de León, Carlos Antonio; Monsiváis, Carlos y Poniatowska, Elena. Crónicas. El EZLN. Documentos y comunicados 1 de enero/8 de agosto de 1994. Fotografías de Paula Haro. México: Editorial Era, 2003. 
Girola, Lidia. "Imaginarios socioculturales de la modernidad. Aportaciones recientes $y$ dimensiones del análisis para la construcción de una agenda de investigación". Revista Sociológica 64 (22). México: Universidad Autónoma MetropolitanaAzcapotzalco. Mayo-agosto 2007: 45-76.

Hobsbawm, Eric. Naciones y nacionalismo desde 1780. Barcelona, España: Editorial Crítica, 1992.

Kruijt, Dirk. Guerrilla: guerra y paz en Centroamérica. Guatemala: F\&G Editores, 2009.

Leyva Solano, Xóchitl. "El neozapatismo de guerrilla a "social movement web". Movimientos armados en México Siglo $X X$. Tomo III. Verónica Oikión Solano y Marta Eugenia García Ugarte (eds.). México. El Colegio de Michoacán-Centro de Investigaciones y Estudios Superiores en Antropología Social (CIESAS), 2006: 725-747.

López, Jaime. 10 años de guerrillas en México (1964-1974). México: Editorial Posada, 1974.

Meiselas, Susan. Nicaragua. España: Editorial Blume, 2008.

Melgar Bao, Ricardo. "La memoria sumergida. Martirologio y sacralización de la violencia en las guerrillas latinoamericanas". Movimientos armados en México Siglo XX. Tomo I. Verónica Oikión Solano y Marta Eugenia García Ugarte (eds.). México: El Colegio de Michoacán-Centro de Investigaciones y Estudios Superiores en Antropología Social (CIESAS), 2006: 29-40.

Melucci, Alberto. "The process of collective identity". Social movements and culture. H. Johnston y B. Klanderman (eds.) Minneapolis, Eeuu: University of Minnesota Press, 1995.

Mendoza, Santa Cruz. Santiago. Insurgentes. Guatemala, la paz arrancada. Santiago, Chile: Ediciones LOM, 2004.

Moya, Rodrigo. "La cámara sola". El catálogo fuera de moda. Homenaje a Rodrigo Moya. Obra fotográfica 1955-1968. México: Consejo Nacional para la
Cultura y las Artes- Instituto Nacional de Antropología e Historia (CONACULTA-INAH), 2002.

Moya, Rodrigo. Ensayo, memoria y crónica. México: Ediciones El Milagro, 2004.

Payeras, Mario. Los pueblos indígenas y la revolución guatemalteca. Ensayos étnicos 1982-1992. Guatemala: Editorial Artemis Edinter, 1998.

Portelli, Alessandro. "La verdad del corazón humano. Los fines actuales de la historia oral". Historia y fuente oral 2. México: Universidad de los Lagos, 2006.

Santa-Cruz Mendoza, Santiago. Insurgentes. Guatemala, la paz arrancada. Santiago de Chile, Chile. Ediciones Lom, 2004: 84.

Schwartz, Howard y Jacobs, Jerry. Sociología cualitativa. Método para la reconstrucción de la realidad. México: Editorial Trillas, 1984.

Sitton, Thad; Mehaffy, George L. y Davis, Ozro Luke. Historia oral. Una guía para profesores (y otras personas). México: Fondo de Cultura Económica, 1999.

Szurmuk, Mónica y MaKee Irwin, Robert (coords.). Diccionario de Estudios Culturales Latinoamericanos. México: Instituto Mora-Siglo XxI Editores, 2009.

Tarrow, Sidney. El poder en movimiento. Los movimientos sociales, la acción colectiva $y$ la política. Madrid: Alianza Editorial, 1997.

\section{ENTREVISTAS:}

César Montes. México DF, 23 de marzo de 2012. Realizada por José Rodrigo Rodríguez López.

César Montes. Ciudad de Guatemala, 22 de julio de 2013. Realizada por José Rodrigo Rodríguez López.

Rodrigo Moya. Centro de las Artes de San Luis Potosí (SLP), 20 de junio de 2012. Realizada por José Rodrigo Rodríguez López.

Rodrigo Moya. Domicilio personal en la ciudad de Cuernavaca, Morelos, 25 de julio de 2012. Realizada por José Rodrigo Rodríguez López.

Fecha de ingreso: 09/01/2013 Fecha de aprobación: 10/01/2014 